\title{
Ankylosing spondylitis and psoriatic arthritis: revisit- ing screening of latent tuberculosis infection and its follow-up during anti-tumor necrosis factor therapy in an endemic area
}

\author{
Andrea Yukie Shimabuco iD, * Ana Cristina de Medeiros-Ribeiro iD, Renata Miossi (iD, Karina Rossi \\ Bonfiglioli iD, Julio Cesar Bertacini de Moraes iD, Celio Roberto Gonçalves (iD, Percival Degrava \\ Sampaio-Barros (iD, Claudia Goldenstein-Schainberg (iD, Fernando Henrique Carlos de Souza iD, \\ Leandro Lara do Prado (iD, Michele Remião Ugolini-Lopes iD, Emily Figueiredo Vieira Neves Yuki iD, \\ Eloisa Bonfa (iD, Carla Gonçalves Schahin Saad (iD \\ Divisao de Reumatologia, Faculdade de Medicina (FMUSP), Universidade de Sao Paulo, SP, BR.
}

Shimabuco AY, Medeiros-Ribeiro AC, Miossi R, Bonfiglioli KR, de Moraes JCB, Gonçalves CR, et al. Ankylosing spondylitis and psoriatic arthritis: revisiting screening of latent tuberculosis infection and its follow-up during anti-tumor necrosis factor therapy in an endemic area. Clinics. 2020;75:e1870

*Corresponding author. E-mail: andreashimabuco@gmail.com

OBJECTIVES: To retrospectively evaluate the performance and distinctive pattern of latent tuberculosis (TB) infection (LTBI) screening and treatment in patients with ankylosing spondylitis (AS) and psoriatic arthritis (PsA) under anti-tumor necrosis factor (TNF) therapy and determine the relevance of re-exposure and other risk factors for TB development.

METHODS: A total of 135 and 83 patients with AS and PsA, respectively, were evaluated for LTBI treatment before receiving anti-TNF drugs via the tuberculin skin test (TST), chest radiography, and TB exposure history assessment. All subjects were evaluated for TB infection at 3-month intervals.

RESULTS: The patients with AS were more often treated for LTBI than were those with PsA (42\% versus $30 \%$, $p=0.043)$. The former also presented a higher frequency of TST positivity $(93 \%$ versus $64 \%, p=0.002)$, although they had a lower frequency of exposure history (18\% versus $52 \%, p=0.027)$ and previous TB $(0.7 \%$ versus $6 \%$, $p=0.03)$. During follow-up [median, 5.8 years; interquartile range (1QR), 2.2-9.0 years], 11/218 (5\%) patients developed active TB (AS, $n=7 ; \operatorname{Ps} A, n=4)$. TB re-exposure was the main cause in seven patients $(64 \%)$ after 12 months of therapy (median, 21.9 months; IQR, 14.2-42.8 months) and five LTBI-negative patients. TB was identified within the first year in four patients (36.3\%) (median, 5.3 months; IQR, 1.2-8.8 months), two of whom were LTBI-positive. There was no difference in the TB-free survival according to the anti-TNF drug type/class; neither synthetic drug nor prednisone use was related to TB occurrence $(p>0.05)$.

CONCLUSION: Known re-exposure is the most critical factor for incident TB cases in spondyloarthritis. There are also some distinct features in AS and PSA LTBI screening, considering the higher frequency of LTBI and TST positivities in patients with AS. Annual risk reassessment taking into consideration these peculiar features and including the TST should be recommended for patients in endemic countries.

KEYWORDS: Latent Tuberculosis; Spondyloarthritis; Tuberculin Skin Test; Mycobacterium tuberculosis; Tumor necrosis factor-alpha.

\section{INTRODUCTION}

Over the last decades, the advent of immunobiological drugs has led to advances in the treatment of spondyloarthritis

Copyright $(2020$ CLINICS - This is an Open Access article distributed under the terms of the Creative Commons License (http://creativecommons.org/licenses/by/ 4.0/) which permits unrestricted use, distribution, and reproduction in any medium or format, provided the original work is properly cited.

No potential conflict of interest was reported.

Received for publication on March 21, 2020. Accepted for publication on July 8,2020

DOI: $10.6061 /$ clinics/2020/e1870
(SpA), especially in the use of anti-tumor necrosis factor (TNF) agents. Drugs, such as infliximab (INF), adalimumab (ADA), etanercept (ETA), golimumab (GOL), and certolizumab pegol (CER), have improved therapeutic objectives and reduced disease progression for affected patients. TNF plays a critical role in the immune mechanism and maintenance of granulomas against Mycobacterium tuberculosis, which is related to the increased risk of latent tuberculosis (TB) infection (LTBI) reactivation in patients using anti-TNF agents in comparison to that in patients using drugs with other mechanisms (1-3).

Recommendations and guidelines were developed to reduce $\mathrm{TB}$ reactivation in patients treated with immunobiological agents. However, local differences among countries 
and risk exposures reinforce that different screening strategies might be needed. In Brazil, owing to the endemic prevalence of TB (34.8 per 100,000 population; São Paulo, 39.6 per 100,000 population) (4) and the increased risk of LTBI reactivation in patients with $\mathrm{SpA}$, the identification and treatment of patients at a higher risk are essential before starting anti-TNF therapy.

Despite LTBI screening before anti-TNF therapy, TB reactivation and new exposure remain a relevant problem. Canadian and American guidelines suggest periodical rescreening for high-TB-risk patients $(5,6)$. The legitimacy of this systematic reassessment is controversial, especially for endemic countries, as there is an evidence of overdiagnosis and consequent unnecessary treatment $(7,8)$ owing to the expected higher frequency of false-positive tuberculin skin test (TST) findings. Solving this problem requires the definition of re-exposure frequency in patients with incident $\mathrm{TB}$ under anti-TNF therapy, despite initial preconized LTBI screening. However, there are no data in the literature regarding the relevance of new TB exposure compared to other possible risk factors in patients with SpA under TNF blockage therapy.

Therefore, the objective of this study was to retrospectively evaluate the performance of LTBI screening in patients with ankylosing spondylitis (AS) and psoriatic arthritis (PsA) under anti-TNF therapy in a TB endemic area and determine the relevance of re-exposure and other causal factors for this complication, aiming to improve the prevention of this infection.

\section{MATERIAL AND METHODS}

\section{Population}

This study retrospectively evaluated 221 patients with AS $(n=138)$ or PsA $(n=83)$ followed up in the Spondyloarthritis Outpatient Clinic from June 2004 to June 2018. The patients were referred to the Immunobiological Drugs Infusion Center (Centro de Dispensação de Medicação de Alto Custo of Hospital das Clínicas da Faculdade de Medicina da Universidade de São Paulo) with indication to undergo biological therapy with anti-TNF drugs for disease activity refractory to conventional treatment. The subjects were followed up at 3-month intervals, with the possibility of unscheduled visits, as necessary. All patients who started anti-TNF therapy were included, except for three patients with AS for not having LTBI screening data documented correctly.

\section{Study design}

The data of the patients with AS and PsA under anti-TNF therapy (INF, ADA, ETA, GOL, and CER) were obtained from an ongoing longitudinal database protocol established in January 2000, which was conducted for all patients and included data on demographics, clinical and laboratory findings, treatments, LTBI screening, and TB occurrence.

According to Brazilian guidelines, all patients with AS and PsA recommended for immunobiological treatment were submitted to LTBI screening before initial therapy (9-13). Active infection was excluded by mycobacterial tests when indicated. LTBI treatment was prescribed to patients with at least one of the following characteristics: positive TST finding ( $\geqslant 5 \mathrm{~mm}$ ); signs of TB sequelae, such as fibrotic lesions on chest radiography (CXR); or previous known exposure to active TB. The latest was defined as present or past household and occupational contact with known TB cases at any time during adulthood. Previously, a report from our department has shown the importance of establishing the exposure history for LTBI treatment in Brazilian patients with rheumatoid arthritis (10). Patients treated for previous TB infection with documented complete therapy and no new contact history were not indicated for LTBI treatment.

The tuberculin used in the Mantoux method (TST) was PPD-RT 23, which was applied intradermally into the volar surface of the left forearm at a dose of $0.1 \mathrm{~mL}$, containing 2-UT tuberculin units and biological equivalence with 5 UT of PPD-S. The result corresponded to the greater transverse diameter of the area of the palpable induration after 48-72 hours $(12,13)$. The readings were performed by a trained nurse.

The LTBI-positive patients received isoniazid (INH) at 5 $\mathrm{mg} / \mathrm{kg}$ up to $300 \mathrm{mg} /$ day for at least 6 months or 180 daily doses according to national guidelines $(12,13)$. The regular use of medication was checked at each medical appointment, in addition to the pharmacy dispensing report. One month of INH treatment was required before the initiation of antiTNF therapy. TST repetition occurred during follow-up only in cases of clinical TB suspicion or owing to extended (>12 months) interruption and re-start of anti-TNF therapy.

Data related to the treatment of LTBI, e.g., adverse effects, such as hepatotoxicity and allergic reactions, and interruption, were also collected.

This study was approved by the Local Ethics Committee on Human Research of the University of São Paulo (CAPPesq) under number 1298/06. All participants provided their written informed consent in compliance with the Helsinki Declaration before initiating biological therapy.

\section{Statistical analysis}

The results were presented as means and standard deviations (SD) or medians and interquartile ranges (IQRs) for continuous variables (age, duration of disease and anti-TNF use, and prednisone dose) and compared using the t-test or Mann-Whitney test for normally and non-normally distributed variables. Conversely, the results were reported as percentages for categorical variables [sex, disease-modifying antirheumatic drug (DMARD) and prednisone use, TST finding of $>5 \mathrm{~mm}$, LTBI, TB exposure, and altered CXR finding] and evaluated using Fisher's exact test or the chisquared test when indicated. Log-rank (Kaplan-Meier) analysis was conducted for TB-free survival on different anti-TNF courses. Statistical significance was considered when the $p$-value was $\leqslant 0.05$. Statistical analyses were performed using the SigmaStat version 3.1 (2005) and GraphPad/Prisma software.

\section{RESULTS}

One hundred and thirty-five patients with AS and eightythree patients with PsA received anti-TNF agents from 2004 to 2018 and were included in this analysis. The patient group was predominantly men $(n=148,68 \%)$. The mean age was 49.2 (SD, 13.1) years, and the mean disease duration was 19.3 (SD, 11.5) years. Half of the patients were treated with the same TNF inhibitor, while $110(50 \%)$ had their drug treatment switched once $(n=67)$, twice $(n=35)$, or thrice $(n=8)$. A total of 422 anti-TNF courses were assessed, including 190 $(45 \%)$ treatments with INF, $128(30 \%)$ with ADA, 92 (22\%) with ETA, $11(3 \%)$ with GOL, and $1(0.2 \%)$ with CER. The median treatment duration was 5.8 (IQR, 2.2-9.0) years (Table 1). Seventy-four percent (three-quarters) used synthetic 
Table 1 - Baseline characteristics.

\begin{tabular}{|c|c|c|c|c|}
\hline & $\mathrm{SpA}(\mathrm{N}=218)$ & AS $(n=135)$ & PsA $(n=83)$ & $p^{*}$ \\
\hline Age (years) & $49.2( \pm 13.1)$ & $47.5( \pm 12.4)$ & $52.2( \pm 13.9)$ & 0.01 \\
\hline Disease duration (years) & $19.3( \pm 11.5)$ & $17.5(11.5-26.3)$ & $17.0(10.3-22.9)$ & 0.35 \\
\hline Male sex (\%) & $149(68 \%)$ & $111(82 \%)$ & $38(46 \%)$ & $<0.01$ \\
\hline Anti-TNF therapy duration (years) & $5.9(2.2-9.0)$ & $6.4(2.2-9.2)$ & $5.4(2.3-8.2)$ & 0.39 \\
\hline Synthetic DMARD use (\%) & $161(74 \%)$ & $99(73 \%)$ & $62(75 \%)$ & 0.75 \\
\hline Prednisone use (\%) & $59(27 \%)$ & $41(30 \%)$ & $18(22 \%)$ & 0.07 \\
\hline
\end{tabular}

Values are expressed as means (standard deviations), medians (interquartile ranges), or percentages. SpA, spondyloarthritis; AS, ankylosing spondylitis; PsA, psoriatic arthritis; DMARD, disease-modifying antirheumatic drug. *AS versus PsA.

Table 2 - LTBI screening in 218 patients with SpA under anti-TNF therapy.

\begin{tabular}{|c|c|c|c|c|}
\hline & $\mathrm{SpA}(\mathrm{N}=218)$ & AS $(n=135)$ & PsA $(n=83)$ & $p^{*}$ \\
\hline LTBI + & $82(38 \%)$ & $57(42 \%)$ & $25(30 \%)$ & 0.04 \\
\hline TST finding, $\geqslant 5 \mathrm{~mm}$ & $69 / 82(84 \%)$ & $53 / 57(93 \%)$ & $16 / 25(64 \%)$ & $<0.01$ \\
\hline Only TST finding, $\geqslant 5 \mathrm{~mm}$ & $58 / 82(71 \%)$ & $46 / 57(81 \%)$ & $12 / 25(48 \%)$ & $<0.01$ \\
\hline Exposure & $23 / 82(28 \%)$ & $10 / 57(18 \%)$ & $13 / 25(52 \%)$ & 0.03 \\
\hline Only exposure & 10/82 (12\%) & $3 / 57(5.2 \%)$ & $7 / 25(28 \%)$ & 0.01 \\
\hline Altered CXR finding & $5 / 82(6.1 \%)$ & $2 / 57(3.5 \%)$ & $3 / 25(12 \%)$ & 0.16 \\
\hline Previous TB & $6 / 218(2.8 \%)$ & $1 / 135(0.7 \%)$ & $5 / 83(6 \%)$ & 0.03 \\
\hline
\end{tabular}

SpA, spondyloarthritis; AS, ankylosing spondylitis; PsA, psoriatic arthritis; LTBI, latent tuberculosis infection; TST, tuberculin skin test; CXR, chest radiography; TB, tuberculosis; TNF, tumor necrosis factor. *AS versus PsA.

DMARDs associated with the biological drug at the beginning of treatment, and sixty-seven percent presented peripheral arthritis.

The patients with PsA were older (52.2 \pm 13.9 versus $47.5 \pm$ 12.4 years, $p=0.01)$, consisted of a lower proportion of men $(46 \%$ versus $82 \%, p<0.01)$, and presented a higher frequency of peripheral arthritis (95\% versus $50 \%, p<0.01)$ than did the patients with AS. The disease duration $(p=0.35)$ and anti-TNF use duration $(p=0.39)$ as well as synthetic DMARD $(p=0.75)$ and prednisone use $(p=0.07)$ and the frequency of anti-TNF drug switch $(p=0.16)$ were similar between the groups (Table 1$)$.

LTBI treatment before anti-TNF therapy was indicated for $82(38 \%)$ patients, being more frequent for the patients with AS $(n=57)$ than for those with PsA $(n=25)(42 \%$ versus $30 \%$, $p=0.04)$, although previous TB was more prevalent in the latter $(0.7 \%$ versus $6 \%, p=0.03)$ (Table 2$)$. The most frequent condition among the patients with LTBI was TST positivity $(69 / 82,84 \%)$, followed by previous contact/exposure (23/ $82,28 \%)$, and TB sequelae findings on CXR $(5 / 82,6.1 \%)$. Furthermore, synthetic DMARD (72\% versus $74 \%, p=1.00$ ) and prednisone use (32\% versus $25 \%, p=0.33$ ) was comparable between the TST-positive and TST-negative patients.

In comparison to that among the patients with PsA, TST positivity was the most prevalent condition among the patients with AS, with positive screening (93\% versus $64 \%$, $p<0.01)$ even as an isolated criterion ( $81 \%$ versus $48 \%, p<0.01)$. Conversely, history of exposure was the most important associated ( $18 \%$ versus $52 \%, p=0.03)$ or single condition found among the patients with PsA $(5.2 \%$ versus $28 \%, p=0.01)$.

According to the recommendations of the Brazilian Society of Rheumatology for rheumatoid arthritis (14), two patients received treatment for LTBI owing to a temporary shortage of the TST, despite no history of exposure or altered CRX findings.

Among the six patients with previous $\mathrm{TB}$, three were retreated with INH owing to a new contact history or an occupational exposure. None of these patients had a new TB episode during follow-up.

\section{TST retest protocol}

According to the internal protocol, the TST was repeated in cases of TB infection suspicion $(n=12)$ or extended $(>12$ months) interruption and re-start of anti-TNF therapy $(n=16)$ and previous negative test findings. Half of the $16(50 \%)$ patients who were re-tested owing to interruption presented TST finding conversion; LTBI treatment was then indicated, and none developed TB until the end of this study. Among the 12 patients investigated for active infection, four patients presented TST finding conversion, being subsequently diagnosed and treated for active TB.

\section{LTBI treatment and side effects}

Of the 82 patients treated for LTBI, only $8.5 \%$ did not complete the INH regimen for the recommended period. Among the reasons for interruption were allergic reactions, transfer to another service, and development of active TB. Hepatotoxicity was seen in $24.3 \%$ of the patients, with most of them having elevated transaminase levels up to twice the normal upper limit. Two patients had INH treatment suspended for higher level elevations. Moreover, the eight patients who subsequently tested positive in the TST completed the LTBI treatment uneventfully.

\section{TB cases}

Eleven $(5 \%)$ patients were diagnosed with TB during follow-up, and one patient had two events. The analysis of possible causal factors revealed no difference in sex, age, disease duration, and co-medication among the patients with or without reactivation/new infection $(p>0.05)$ (Table 3$)$. The assessment of the 422 anti-TNF courses revealed the presence of monoclonal and non-monoclonal anti-TNF antibodies in the general sample $(p=0.69)$ and that the patients with AS $(p=0.71)$ and PsA $(p=0.98)$ had a comparable TB-free survival.

\section{Anti-TNF therapy duration and TB}

During follow-up, 4/12 (33.3\%) TB episodes occurred within the first year, at a median duration of 5.3 (IQR, 1.2-8.8) 
Table 3 - Comparison between 11 patients with and 207 patients without TB during follow-up.

\begin{tabular}{lccr}
\hline & TB $+(\mathbf{n = 1 1 )}$ & TB $-(\mathbf{n = 2 0 7 )}$ & $\boldsymbol{p}$ \\
\hline Age (years) & $46.4(13.1)$ & $49.4(13.2)$ & 0.46 \\
Disease duration (years) & $16.5(9.8-26.5)$ & $17.5(10.5-24.5)$ & 0.75 \\
Male sex (\%) & $10(91 \%)$ & $139(67 \%)$ & 0.18 \\
Anti-TNF therapy duration (years) & $1.3(0.7-3.5)$ & $6.3(2.5-9.1)$ & $<0.01$ \\
Synthetic DMARD use (\%) & $7(64 \%)$ & $154(74 \%)$ & 0.48 \\
Prednisone use (\%) & $2(18 \%)$ & $57(28 \%)$ & 0.73 \\
Prednisone dose (mg) & $15(10-20)$ & $10(5-10)$ & 0.21 \\
LTBI & $4(36 \%)$ & $80(39 \%)$ & 1.00 \\
\hline
\end{tabular}

TB, tuberculosis; TNF, tumor necrosis factor; DMARD, disease-modifying antirheumatic drug; LTBI, latent tuberculosis infection.

Table 4 - Description of the TB cases.

\begin{tabular}{|c|c|c|c|c|c|c|c|c|c|}
\hline & & Sex & $\begin{array}{c}\text { Age } \\
\text { (years) }\end{array}$ & Occupation & Risk factors & LTBI & $\begin{array}{l}\text { Anti-TNF } \\
\text { drug }\end{array}$ & $\begin{array}{l}\text { TNFi-TB duration } \\
\text { (months) }\end{array}$ & Infection \\
\hline 1 & PsA & $M$ & 45 & Salesman & $\begin{array}{l}\text { Household contact, } \\
\text { Smoking }\end{array}$ & pos & ADA & 20.6 & Pleural \\
\hline 2 & PsA & $M$ & 69 & Retired & $\begin{array}{c}\text { DM, } \\
\text { Schistosomiasis }\end{array}$ & neg & INFLIXI & 3.7 & Peritoneal \\
\hline 3 & PsA & $M$ & 55 & Unknown & None & neg & INFLIXI & 15.5 & Pulmonary \\
\hline 4 & PsA & $\mathrm{F}$ & 52 & Unknown & $\begin{array}{c}\text { DM, } \\
\text { Smoking }\end{array}$ & pos & INFLIXI & 32.4 & Pulmonary \\
\hline 5 & AS & $M$ & 36 & Mechanic & None & neg & ADA & 22.2 & Pulmonary \\
\hline 6 & AS & $M$ & 53 & Retired & DM & neg & ADA & 42.8 & Pulmonary \\
\hline 7 & AS & $M$ & 59 & Retired & None & neg & INFLIXI & 7.0 & Pulmonary \\
\hline 8 & AS & $M$ & 46 & Unknown & Drug addiction, Alcoholism & pos & ADA & 2.3 & Pleural \\
\hline 9 & AS & M & 37 & Physician & Occupational exposure & pos & ADA & 8.8 & Pleural \\
\hline 10 & AS & M & 36 & Hairdresser & $\begin{array}{c}\text { DM, } \\
\text { Obesity }\end{array}$ & neg & ETA & 23.3 & Spondylodiscitis \\
\hline 11 & AS & M & 21 & Student & None & neg & INFLIXI & 14.2 & Pulmonary \\
\hline
\end{tabular}

TB, tuberculosis; LTBI, latent tuberculosis infection; PsA, psoriatic arthritis; AS, ankylosing spondylitis; ADA, adalimumab; INFLIXI, infliximab; ETA, etanercept; DM, diabetes mellitus; neg, negative; pos, positive.

months after initiating anti-TNF therapy. Fifty percent of the patients received INH previously; one of these patients had a confirmed report of irregular use of INH. More prolonged therapy was observed in most patients $(8 / 12,66.7 \%)$, with a median duration of 22.8 (IQR, 17.7-27.2) months, including the patient with two events. Considering the seven patients, the median duration was 21.9 (IQR, 14.2-42.8) months. Two $(28 \%)$ of these patients were LTBI-positive and treated with INH as recommended. The frequency of extra-pulmonary TB was $25 \%(2 / 8)$ among the patients with TB diagnosed after 12 months and $75 \%(3 / 4)$ among those diagnosed up to 1 year under anti-TNF therapy.

Table 4 describes the active TB cases with their respective risk factors. The majority of the patients $(7 / 11,64 \%)$ had identifiable isolated or concomitant risk factors: diabetes mellitus $(n=4)$; smoking $(n=2)$; occupational exposure $(n=1)$; drug addiction $(n=1)$; schistosomiasis $(n=1)$; alcoholism $(n=1)$; household contact $(n=1)$; and obesity $(n=1)$.

\section{DISCUSSION}

In this study, we provided novel evidence that known re-exposure is the most critical risk factor for incident TB in patients with SpA under long-term anti-TNF therapy.

Brazil is among the 30 high-TB-burden countries prioritized by the World Health Organization, encompassing $80 \%$ of the global TB cases. The risk for TB among patients with inflammatory arthritis is higher than that among the general population, varying according to the region or country of the study $(1,2)$. However, no study has yet been performed on the incidence of TB among patients with SpA in Brazil.

The great advantage of this study is the consistent and complete LTBI screening for all patients using a standard protocol recommended by Brazilian guidelines (11) and the national recommendation for TB control $(12,13)$. The nonhomogeneous use of an LTBI screening protocol in previous studies hampers the interpretation of their findings on the relevance of each risk factor. A screening limited to a few parameters was reported by Shobha et al. (15), and a low adherence to screening was also observed in the Brazilian registry (16).

A long-term follow-up was also essential for this evaluation, as TB re-exposure is considered after at least 12 months $(17,18)$, and it has already been shown that the risk remains throughout the treatment (19). The lack of information regarding the treatment duration $(3,16,20)$ precludes an accurate evaluation of the importance of re-exposure in the context of incident TB. In addition, all but one study (21) evaluated SpA associated with other rheumatic diseases $(17,22-24)$ without clear discrimination of the TB risk among each disorder. Unbalanced intrinsic disease features, such as age, occupational exposure, and glucocorticoid and DMARD use, in different illnesses are relevant confounding variables in the evaluation of risk factors $(1,9)$. Moreover, the report focusing on AS is an extensive case-control study in Korea, analyzing solely the incidence of TB related to the use of antiTNF drugs (21).

LTBI was seen in more than a third of the patients with $\mathrm{SpA}$, a finding similar to the previously reported for 
Brazilian (17), Spanish (24), South Korean (25), and Indian patients (26). We also confirmed that TST positivity was more frequent in the patients with AS than in the patients with PsA (17) possibly owing to the anergy already known in this latter arthropathy, as observed in rheumatoid arthritis (27). This distinct characteristic of PsA reinforces the relevance of exposure history screening in the evaluation of candidates for immunobiological therapy in comparison to AS.

Recent publications suggested that IGRA combined with the TST may be superior to the tests used separately $(24,28-$ 30 ), although the TST has already been proven useful for screening in endemic countries $(3,10,12,13,27)$. In Brazil, owing to the unavailability of IGRA in the public health system, the TST remains the main tool for LTBI screening.

With this strict protocol and the indicated treatment of LTBI before initiating TNF blockage therapy, eleven $(5 \%)$ patients developed active TB during a median follow-up of more than 5 years. This frequency is higher than that reported in other endemic countries for rheumatic diseases $(15,21,31$, 32). The most likely explanation is probably related to the long-term follow-up (28), biological class used (21), and concomitant analysis of distinct diseases in previous studies $(15,31,32)$.

The analysis of the risk factors for incident TB revealed that known re-exposure is the most critical cause of this complication. It occurred in a median period of 2 years, and we confirmed the previous observation that new TB infections mostly present as a pulmonary disease $(18,33,34)$. In contrast, $\mathrm{TB}$ reactivation was observed in approximately one-third of the patients with $\mathrm{TB}$, and the majority of cases were extra-pulmonary with a median of 5.3 months of exposure. Non-adherence to LTBI treatment is likely the cause in this group, as half of the patients had positive screening findings. Despite the prescription and dispensing of medication and checking in each medical appointment, it is not straightforward to ensure the correct use of INH. Poor adherence to LTBI treatment is an obstacle among individuals with high-risk TB diseases. Indeed, Sandgren et al. (35) found that the proportions of individuals completing LTBI treatment may be as low as 39\% for the general population and $48 \%$ for case contacts.

Host-related risk factors may have contributed to the higher incidence of TB observed in this study, as two-thirds of the patients reported at least one of the following wellknown risk factors: smoking, drug addiction, alcoholism, HIV infection, malnutrition, diabetes mellitus, and chronic renalfailure $(1,36)$. The lack of age- and sex-matched control group is a limitation and precludes the analysis of the real relevance of these factors.

Therefore, it is unquestionably necessary to reinforce the contact history and risk exposure approach as a more effective screening and preventive tool during follow-up. In addition to establishing at-risk populations that could benefit from intensive supervision of adherence to prophylaxis and periodic re-evaluation of LTBI, the preference for non-antiTNF biological drugs, such as anti-IL-17 and anti-IL-12/23, which are not associated with an increased risk of TB $(1,2)$, should be considered.

There was no difference found in the TB-free survival according to the type or class of anti-TNF drug used, and the small representation of ETA in our sample may account for this finding. This drug was reported to be associated with a lower incidence of TB than were other monoclonal anti-TNF antibodies in rheumatic diseases (1,2,37-39). The concomitant use of synthetic DMARDs with biological therapy was not associated herein with a higher frequency of $\mathrm{TB}$, a finding similar to that reported by the CORRONA registry (40) and distinct to that observed in an Italian systematic review (41).

Brazilian guidelines do not indicate the programmed TST repetition; however, prescription of INH was essential in eight patients before the reintroduction of anti-TNF therapy after a period without medication, and active TB diagnosis was necessary in four patients with negative test findings in the baseline. These cases support the notion that re-exposure to $M$. tuberculosis remains a threat to the prevention in endemic countries and that as recommended by some guidelines $(5,6,42,43)$, LTBI re-evaluation may identify patients at a higher risk of developing active TB in a long-term follow-up.

Despite the previously defined LTBI screening protocol, a retrospective analysis was conducted in this study, which limits some results and conclusions, such as those for the risk factors. Further, the unavailability of other tests (IGRA, QuantiFERON-TB Gold In-Tube test, and T-SPOT.TB assay) impaired the comparison with the TST.

Herein, we provided new data demonstrating that known re-exposure is the most crucial factor for incident $\mathrm{TB}$ cases in patients with SpA under anti-TNF therapy, despite the screening and treatment of LTBI before initiating TNF blockage therapy. We also confirmed some distinct features in AS and PsA LTBI screening. Annual risk reassessment taking into consideration these peculiar features and including the TST should then be recommended for these patients in endemic countries.

\section{ACKNOWLEDGMENTS}

This work was supported by grants from Fundacao de Amparo a Pesquisa do Estado de São Paulo (FAPESP \#2015/03756-4 to E.B.), Conselho Nacional de Desenvolvimento Científico e Tecnológico (CNPq grants \#305068/2014-8 to E.B.), and the Frederico Foundation (to PDSB, EB, and CGSS).

\section{AUTHOR CONTRIBUTIONS}

Shimabuco AY: study conceptualization and design, assistance in subject recruitment, Q9 acquisition of subject and data, interpretation of data, and drafting of the manuscript.

Medeiros-Ribeiro AC: study conceptualization and design, assistance in subject recruitment, interpretation of data, and drafting of the manuscript. MiossiR: assistance in subject recruitment, interpretation of data, and drafting of the manuscript.

BonfiglioliKR: study conceptualization and design, assistance in subject recruitment, interpretation of data, and drafting of the manuscript.

MoraesJC: assistance in subject recruitment, interpretation of data, and drafting of the manuscript.

GoncalvesCR: assistance in subject recruitment and revision of the manuscript. Sampaio-BarrosPD: assistance in subject recruitment and revision of the manuscript.

Goldenstein-SchainbergC: assistance in subject recruitment and revision of the manuscript.

SouzaFH: assistance in subject recruitment, interpretation of data, and revision of the manuscript.

PradoLL: assistance in subject recruitment, interpretation of data, and revision of the manuscript.

LopesMR: assistance in subject recruitment and drafting of the manuscript. YukiEF: assistance in subject recruitment, interpretation of data, and drafting of the manuscript.

BonfaE: study conceptualization and design, assistance in subject recruitment, interpretation of data, and drafting of the manuscript.

SaadCG: study conceptualization and design, assistance in subject recruitment, interpretation of data, and drafting of the manuscript. 


\section{REFERENCES}

1. Cantini F, Nannini C, Niccoli L, Iannone F, Delogu G, Garlaschi G, et al. Guidance for the management of patients with latent tuberculosis infection requiring biologic therapy in rheumatology and dermatology clinical practice. Autoimmun Rev. 2015;14:503-9.

2. Minozzi S, Bonovas S, Lytras T, Pecoraro V, González-Lorenzo M, Bastiampillai AJ, et al. Risk of infections using anti-TNF agents in rheumatoid arthritis, psoriatic arthritis, and ankylosing spondylitis: a systematic review and meta-analysis. Expert Opin Drug Saf. 2016;15(sup1):11-34. https: / doi.org/10.1080/14740338.2016.1240783

3. Dixon WG, Hyrich KL, Watson KD, Lunt M, Galloway J, Ustianowski A, et al. Drug-specific risk of tuberculosis in patients with rheumatoid arthritis treated with anti-TNF therapy: results from the British Society for Rheumatology Biologics Register (BSRBR). Ann Rheum Dis. 2010;69(3): 522-8. https://doi.org/10.1136/ard.2009.118935

4. Ministério da Saúde. Brasil Livre da Tuberculose: evolução dos cenários epidemiológicos e operacionais da doença. Brazil, Ministerio: http://por talarquivos2.saude.gov.br/images/pdf/2019/marco/22/2019-009.pdf

5. Bombardier C, Hazlewood GS, Akhavan P, Schieir O, Dooley A, Haraoui $\mathrm{B}$, et al. Canadian Rheumatology Association Recommendations for the Pharmacological Management of Rheumatoid Arthritis with Traditional and Biologic Disease-modifying Antirheumatic Drugs: Part II Safety. J Rheumatol. 2012;39:1583-602. https://doi.org/10.3899/jrheum.120165

6. Singh JA, Furst DE, Bharat A, Curtis JR, Kavanaugh AF, Kremer JM, et al. 2012 update of the 2008 American College of Rheumatology recommendations for the use of disease-modifying antirheumatic drugs and biologic agents in the treatment of rheumatoid arthritis. Arthritis Care Res. 2012:64(5):625-39.

7. Park JH, Seo GY, Lee JS, Kim TH, Yoo DH. Positive conversion of tuberculin skin test and performance of interferon release assay to detect hidden tuberculosis infection during anti-tumor necrosis factor agent trial. J Rheumatol. 2009;36(10):2158-63. https://doi.org/10.3899/jrheum .090150

8. Chen DY, Shen GH, Hsieh TY, Hsieh CW, Lan JL. Effectiveness of the combination of a whole-blood interferon-gamma assay and the tuberculin skin test in detecting latent tuberculosis infection in rheumatoid arthritis patients receiving adalimumab therapy. Arthritis Rheum. 2008;59(6):800-6.

9. Cecconi M, Ranza R, Titton DC, Moraes JCB, Bertolo M, Bianchi W, et al. Incidence of Infectious Adverse Events in Patients with Rheumatoid Arthritis and Spondyloarthritis on Biologic Drugs-Data From the Brazilian Registry for Biologics Monitoring. J Clin Rheumatol. 2018.

10. Bonfiglioli KR, Ribeiro AC, Moraes JC, Saad CG, Souza FH, Calich AL, et al. LTBI screening in rheumatoid arthritis patients prior to anti-TNF treatment in an endemic area. Int J Tuberc Lung Dis. 2014;18(8):905-11.

11. Mota LM, Cruz BA, Brenol CV, Pollak DF, Pinheiro Gda R, Laurindo IM, et al. Segurança do uso de terapias biológicas para o tratamento de artrite reumatoide e espondiloartrites [Safe use of biological therapies for the treatment of rheumatoid arthritis and spondyloarthritis]. Rev Bras Reumatol. 2015;55(3):281-309.

12. Ministério da Saúde. Guidelines for the control of tuberculosis in Brazil, 2011. Ministério da Saúde, Brasília, Brazil (2011). Brazil, Ministerio: http://portal.saude.gov.br/portal/arquivos/pdf/manual_de_recomenda coes_tb.pdf

13. Ministério da Saúde. Protocol for Latent Tuberculosis Infection surveillance in Brazil. Ministério da Saúde, Brasília, Brazil (2018). Brazil, Ministerio: http://portalarquivos2.saude.gov.br/images/pdf/2018/setembro/28/Pro tocolo-de-vigil--ncia-da-ILTB-2018.pdf

14. da Mota LM, Cruz BA, de Albuquerque CP, Goncalves D, Laurindo IM, Pereira IA, et al. Orientações preliminares da Sociedade Brasileira de Reumatologia para avaliação e tratamento da tuberculose infecção latente em pacientes com artrite reumatoide na indisponibilidade do teste tuberculínico. [Preliminary guidelines of the Brazilian Society of Rheumatology for evaluation and treatment of tuberculosis latent infection in patients with rheumatoid arthritis, in face of unavailability of the tuberculin skin test]. Rev bras reumatol. 2015;55(4):390-3. https://doi.org/ 10.1016/j.rbr.2015.01.006

15. Shobha V, Chandrashekara S, Rao V, Desai A, Jois R, Dharmanand BG, et al. Biologics and risk of tuberculosis in autoimmune rheumatic diseases: A real-world clinical experience from India. Int J Rheum Dis. 2019;22(2):280-287. https://doi.org/10.1111/1756-185X.13376

16. Ribeiro ACM, Bredemeier M, Valim V, Pinheiro MM, Macieira C, Duarte AP, et al. SAT0123 Risk for tuberculosis during treatment with biological therapy: is it time for reviewing screening protocol? - Results from Brazilian Registry of Biological Therapies in Rheumatic Diseases. (BIOBADABRASIL) Annals of the Rheumatic Diseases. 2019;78:1129-1130.

17. Gomes CM, Terreri MT, Moraes-Pinto MI, Barbosa C, Machado NP, Melo $\mathrm{MR}$, et al. Incidence of active mycobacterial infections in Brazilian patients with chronic inflammatory arthritis and negative evaluation for latent tuberculosis infection at baseline--a longitudinal analysis after using TNFa blockers. Mem Inst Oswaldo Cruz. 2015;110(7):921-8. https://doi.org/ 10.1590/0074-02760150235
18. Soare A, Gheorghiu AM, Aram V, Bumb cea D, Dobrot R, Oneaţ R, et al. Risk of active tuberculosis in patients with inflammatory arthritis receiving TNF inhibitors: a look beyond the baseline tuberculosis screening protocol. Clin Rheumatol. 2018;37(9):2391-2397. https://doi. org /10.1007/s10067-017-3916-y

19. Wallis RS. Tumour necrosis factor antagonists: structure, function, and tuberculosis risks. Lancet Infect Dis. 2008;8(10):601-11. https://doi.org/ 10.1016/S1473-3099(08)70227-5

20. Garziera G, Morsch ALB, Otesbelgue F, Staub FL, Palominos PE, Brenol $\mathrm{CV}$, et al. Latent tuberculosis infection and tuberculosis in patients with rheumatic diseases treated with anti-tumor necrosis factor agents. Clin Rheumatol. 2017;36(8):1891-1896.

21. Kim EM, Uhm WS, Bae SC, Yoo DH, Kim TH. Incidence of tuberculosis among Korean patients with ankylosing spondylitis who are taking tumor necrosis factor blockers. J Rheumatol. 2011;38(10):2218-23. https:/ / doi.org/10.3899/jrheum.110373

22. Hsia EC, Cush JJ, Matteson EL, Beutler A, Doyle MK, Hsu B, et al. Comprehensive tuberculosis screening program in patients with inflammatory arthritis treated with golimumab, a human anti-tumor necrosis factor antibody, in phase III clinical trials. Arthritis Care Res (Hoboken). 2013;65(2):309-13

23. Kisacik B, Pamuk ON, Onat AM, Erer SB, Hatemi G, Ozguler Y, et al. Characteristics Predicting Tuberculosis Risk under Tumor Necrosis Factor- $\alpha$ Inhibitors: Report from a Large Multicenter Cohort with High Background Prevalence. J Rheumatol. 2016;43(3):524-9. https://doi.org/ 10.3899 /jrheum.150177

24. Muñoz L, Casas S, Juanola X, Bordas X, Martinez C, Santin MPrevention of Anti-TNF-Associated Tuberculosis Study Team of Bellvitge University Hospital. Prevention of anti-tumor necrosis factor-associated tuberculosis: a 10-year longitudinal cohort study. Clin Infect Dis. 2015;60:349-56. https://doi.org/10.1093/cid/ciu796

25. Kim JH, Cho SK, Han M, Choi CB, Kim TH, Jun JB, et al. Factors influencing discrepancies between the QuantiFERON-TB gold in tube test and the tuberculin skin test in Korean patients with rheumatic diseases. Semin Arthritis Rheum. 2013;42(4):424-32. https://doi.org/10.1016/j.semar thrit.2012.07.001

26. Malaviya AN, Aggarwal VK, Rawat R, Baghel S, Thakran R, Zaheer Q, et al. Screening for latent tuberculosis infection among patients with rheumatoid arthritis in the era of biologics and targeted synthetic diseasemodifying anti-rheumatic drugs in India, a high-burden TB country: The importance of Mantoux and Quantiferon-TB Gold tests. Int J Rheum Dis. 2018;21(8):1563-1571. https://doi.org/10.1111/1756-185X.13261

27. Laurindo IM, Seiscento M, Bombardia S, Souza TNL, Eluf-Neto J, Halpern ASR, et al. Diagnosis of latent tuberculosis in rheumatoid arthritis (RA) patients:tuberculintest(PPD)assessment. EULAR 2004 [THU0235] https:// scientific.sparx-ip.net/archiveeular $/ ? \mathrm{c}=\mathrm{a} \&$ searchfor=laurindo\&view $=1 \&$ item $=2004 \mathrm{THU} 0235$.

28. Mikulska M, Lanini S, Gudiol C, Drgona L, Ippolito G, Fernández-Ruiz $\mathrm{M}$, et al. ESCMID Study Group for Infections in Compromised Hosts (ESGICH) Consensus Document on the safety of targeted and biological therapies: an infectious diseases perspective (Agents targeting lymphoid cells surface antigens [I]: CD19, CD20 and CD52). Clin Microbiol Infect. 2018;4 Suppl 2:S71-S82. https://doi.org/10.1016/j.cmi.2018.02.003

29. Mariette X, Baron G, Tubach F, Lioté F, Combe B, Miceli-Richard C, et al. Influence of replacing tuberculin skin test with ex vivo interferon $\gamma$ release assays on decision to administer prophylactic tuberculosis antibiotics before anti-TNF therapy. Ann Rheum Dis. 2012;71(11):1783-90. https:// doi.org/10.1136/annrheumdis-2011-200408

30. Hsia EC, Schluger N, Cush JJ, Chaisson RE, Matteson EL, Xu S et al. Interferon- $\gamma$ release assay versus tuberculin skin test prior to treatment with golimumab, a human anti-tumor necrosis factor antibody, in patients with rheumatoid arthritis, psoriatic arthritis, or ankylosing spondylitis. Arthritis Rheum. 2012;64(7):2068-77. https://doi.org/10.1002/ art.34382

31. Wang X, Wong SH, Wang XS, Tang W, Liu CQ, Niamul G, et al. Risk of tuberculosis in patients with immune-mediated diseases on biological therapies: a population-based study in a tuberculosis endemic region Rheumatology (Oxford). 2019:58(5):803-810.

32. Jung SM, Ju JH, Park MS, Kwok SK, Park KS, Kim HY, et al. Risk of tuberculosis in patients treated with anti-tumor necrosis factor therapy: a nationwide study in South Korea, a country with an intermediate tuberculosis burden. Int J Rheum Dis. 2015;18(3):323-30. https://doi.org/ 10.1111/1756-185X.12530

33. Yonekura CL, Oliveira RDR, Titton DC, Ranza R, Ranzolin A, Hayata AL, et al. Incidence of tuberculosis among patients with rheumatoid arthritis using TNF blockers in Brazil: data from the Brazilian Registry of Biological Therapies in Rheumatic Diseases (Registro Brasileiro de Monitoração de Terapias Biológicas - BiobadaBrasil). Rev Bras Reumatol Engl Ed. 2017;57:477-483. https:/ / doi.org/10.1016/j.rbr.2017.05.003

34. Sartori NS, de Andrade NPB, da Silva Chakr RM. Incidence of tuberculosis in patients receiving anti-TNF therapy for rheumatic diseases: a systematic review. Clin Rheumatol. 2020;39(5):1439-1447 
35. Sandgren A, Vonk Noordegraaf-Schouten M, van Kessel F, Stuurman A, Oordt-Speets A, van der Werf MJ. Initiation and completion rates for latent tuberculosis infection treatment: a systematic review. BMC Infect Dis. 2016;16:204. https://doi.org/10.1186/s12879-016-1550-y

36. Leung CC, Rieder HL, Lange C, Yew WW. Treatment of latent infection with Mycobacterium tuberculosis: update 2010. Eur Respir J. 2011; 37(3):690-711. https://doi.org/10.1183/09031936.00079310

37. Gomez-Reino J, Carmona L, Angel Descalzo M. Biobadaser Group. Risk of tuberculosis in patients treated with tumor necrosis factor antagonists due to incomplete prevention of reactivation of latent infection. Arthritis Rheum. 2007;57(5):756-61. https://doi.org/10.1002/art.22768

38. Cantini F, Niccoli L, Goletti D. Adalimumab, etanercept, infliximab, and the risk of tuberculosis: data from clinical trials, national registries, and postmarketing surveillance. J Rheumatol Suppl. 2014;91:47-55. https:// doi.org/10.3899/jrheum.140102

39. Solovic I, Sester M, Gomez-Reino JJ, Rieder HL, Ehlers S, Milburn HJ, et al. The risk of tuberculosis related to tumour necrosis factor antagonist therapies: a TBNET consensus statement. Eur Respir J. 2010;36(5):1185206. https:/ / doi.org/10.1183/09031936.00028510
40. Greenberg JD, Reed G, Kremer JM, Tindall E, Kavanaugh A, Zheng C, et al. Association of methotrexate and tumour necrosis factor antagonists with risk of infectious outcomes including opportunistic infections in the CORRONA registry. Ann Rheum Dis. 2010;69(2):380-6. https://doi.org/ 10.1136/ard.2008.089276

41. Lorenzetti R, Zullo A, Ridola L, Diamanti AP, Laganà B, Gatta L, et al. Higher risk of tuberculosis reactivation when anti-TNF is combined with immunosuppressive agents: a systematic review of randomized controlled trials. Ann Med. 2014;46(7):547-54. https://doi.org/10.3109/ 078 53890.2014.941919

42. Furst DE, Keystone EC, So AK, Braun J, Breedveld FC, Burmester GR, et al. Updated consensus statement on biological agents for the treatment of rheumatic diseases, 2012. Ann Rheum Dis. 2013;ii2-34. https://doi. org/10.1136/annrheumdis-2013-203348

43. Iannone F, Cantini F, Lapadula G. Diagnosis of latent tuberculosis and prevention of reactivation in rheumatic patients receiving biologic therapy: international recommendations. J Rheumatol Suppl. 2014;91:41-6. https://doi.org/10.3899/jrheum.140101 